\title{
Cien declaraciones de las Asambleas Plenarias del Episcopado Chileno (1962-2010): Notas para una hermenéutica teológica
}

\author{
Fernando Berríos Medel \\ FACULTAD DE TEOLOGÍA \\ PONTIFICIA UNIVERSIDAD CATÓLICA DE CHILE
}

Referirse a las declaraciones de las Asambleas Plenarias de la Conferencia Episcopal de Chile a lo largo de cinco décadas aparece como un desafío mayor y no exento de complejidad. Visto con distancia, el medio siglo abarcado ha sido especialmente intenso y significativo en la historia de nuestra patria y en la del mundo en que ella está inserta.

La serie de declaraciones comienza en los albores de los sesenta, una década que traería transformaciones profundas en la vida de las naciones y de la Iglesia en particular, y se prolonga hasta fines de 2010, año en que la sociedad chilena toda, enfrentada a una gran catástrofe natural, tuvo que saber dar muestras de entereza y de solidaridad. Se ha abierto así, como han señalado los obispos en su centésima Asamblea Plenaria, un espacio a la esperanza como "punto de partida de una etapa nueva de la historia de Chile» ${ }^{1}$. Resulta especialmente significativo que al final de todo este recorrido, atravesado también por momentos de crisis y de situaciones problemáticas o francamente conflictivas para la sociedad chilena y para la Iglesia en ella inserta, la última palabra sea la esperanza. Esperanza como actitud fundamental ante el presente y el futuro, pero también como un llamado que es necesario acoger activamente, favoreciendo las condiciones que la hagan posible: «no hay esperanza sin compromiso con la verdad y con la honestidad de la escucha y el diálogo... No hay esperanza sin intentar entender lo que le pasa al otro,

\footnotetext{
"Esperemos con constancia" (Rm 8,25), Punta de Tralca, noviembre 2010, 4. (En adelante, los documentos de las Asambleas Plenarias serán citados con su título, lugar, mes y año de la Asamblea respectiva y, si está indicado, el número del parágrafo citado.)
} 
en particular a aquellos que reciben la peor parte de la vida en nuestra tierra...». Es que, en definitiva, para los obispos chilenos «la esperanza hunde su consistencia en la justicia y en la búsqueda del bien de todos». Solo en esa perspectiva los cristianos podremos ser, en nuestra patria, «testigos de las esperanza»".

Asumiendo la complejidad de esta franja de nuestra historia y de la historia de la reflexión que los Pastores han hecho sobre ella, y consciente de la imposibilidad de hacernos cargo de todo ello en los límites de un texto que no puede ser muy extenso, se intentará articular una aproximación que destaque a grandes trazos el contenido de los documentos $\mathrm{y}$, sobre todo, la reflexión teológica que ellos pueden suscitar hoy.

Propongo una reflexión en tres pasos: primero, una mirada de conjunto a las principales temáticas de cada década y a su enfoque por parte del episcopado; segundo, la mención y un breve análisis de las principales claves teológicas en el conjunto de los documentos; y tercero -a modo de conclusión-, algunas perspectivas o desafíos eclesiales para el futuro.

\section{UNA MIRADA DE CONJUNTO}

Un análisis detallado de todas las temáticas que las Asambleas Plenarias han abarcado en estas cinco décadas superaría con mucho las posibilidades de un breve artículo, como pretende ser este. En las siguientes páginas se intentará, por tanto, una mirada más bien general que nos permita identificar y destacar las principales ideas-fuerza de las declaraciones del episcopado chileno en todo este tiempo. En un esfuerzo por ordenar esta aproximación, el análisis se hará agrupando los documentos por decenios, siguiendo criterios históricos y contextuales amplios.

Una lectura general de los textos en esta perspectiva lleva a destacar desde el comienzo un aspecto básico, aunque no obvio: que en ellos se da una evolución, tanto en las temáticas como en la terminología y en el estilo utilizados, reflejando así muy elocuentemente el contexto histórico y eclesial en que los documentos han sido formulados. Ello habla muy bien de estas declaraciones, pues indica la fuerte impronta encarnatoria de la reflexión de los pastores en su caminar en medio del pueblo de Dios a través de todos estos años. No se trasunta en los tex-

2 Todas las citas del párrafo en ibid., 3. 
tos la figura de una Iglesia inmutable, sino la de una Iglesia más bien dinámica, que se ha sentido desafiada a responder a los llamados del Señor en la novedad permanente del acontecer de la historia de Chile. Ello no implica, por cierto, que las respuestas dadas hayan sido siempre e indudablemente las más adecuadas o que siempre hayan estado a la altura de los desafíos históricos, pero sí es claro un esfuerzo permanente y explícito en tal perspectiva.

1.1. La década de los sesenta: los obispos ante un gran vuelco en gestación

La década inicial de las Asambleas Plenarias, los sesenta, es, como sabemos, una década decisiva del siglo XX. Los documentos reflejan mucho de esa intensidad, tanto del ambiente cultural y político convulsionado, como del espíritu que movía por entonces a la Iglesia en torno a la realización de las sesiones del Concilio Vaticano $\mathrm{II}^{3}$. Al mismo tiempo, el lenguaje utilizado en las declaraciones delata a una Iglesia que está a medio camino entre una configuración tradicional y los movimientos de renovación en ciernes. Se plantean, por ejemplo, preocupaciones propiamente intraeclesiales como el estilo de vida de los sacerdotes o el cambio o no del hábito eclesiástico ${ }^{4}$ y luego, aunque todavía germinalmente, temas del todo nuevos y desafiantes, como la Iglesia «de los pobres» o la relación entre cristianismo y marxismo 5 .

El tema de fondo es, claramente, la redefinición profunda -y que está en las bases mismas del Concilio Vaticano II- de la relación Iglesiamundo, o mejor: de la autocomprensión de la Iglesia en un mundo que está en medio de un proceso de profundas e intensas transformaciones sociales y culturales. En este sentido, se entiende que el tema de la vestimenta de los presbíteros y de los religiosos no sea visto como algo banal, sino como un signo de la comprensión de sus roles en una renovada situación cultural y eclesial. ¿Hasta dónde llegar con las adaptaciones

3 Un primer testimonio claro en esta línea es el Edicto emanado de la 2a Asamblea Plenaria, Santiago, agosto 1962, en el que los obispos invitan a sumarse con el ánimo y con oraciones en pos del éxito de lo que consideran «uno de los hechos de mayor envergadura para la historia de la Iglesia en nuestro tiempo y para un feliz desarrollo del mundo contemporáneo».

4 Circular al clero, de la Asamblea Plenario del Episcopado, sin indicación de lugar, abril 1963; Declaración de los Obispos de Chile, La Florida (Santiago), octubre 1968.

5 Orientaciones Pastorales I: Imagen de la Iglesia, Chillán, mayo 1968. 
a los nuevos tiempos, que en estos momentos aparece como un desafío ineludible para la Iglesia y sus estructuras? Es evidente que la respuesta a esta pregunta de fondo se busca todavía en el marco de una mentalidad en que la estructura jerárquica y clerical de la Iglesia aparece como decisiva para la definición de su sentido y misión en el mundo. Ante los desafíos y tendencias que se reconocen en dicho contexto de cambios -secularización, razón en conflicto con la fe, tecnicismo utilitario, politización, etc., con sus graves consecuencias $-{ }^{6}$, el episcopado destaca que una correcta concepción del «estilo de vida sacerdotal $»^{7}$ será un elemento fundamental para una adecuada respuesta como Iglesia.

Pero al mismo tiempo, en esta década -y ya en sus comienzos- la reflexión y la acción de la jerarquía de la Iglesia chilena se adentran en temas sociales muy candentes, como el problema del campesinado ${ }^{8}$. Recordemos a este propósito que fueron dos obispos, Manuel Larraín y Raúl Silva Henríquez, los pioneros de la reforma agraria en Chile? . Esto indica que más que una mezcla de intereses y de preocupaciones en las intervenciones episcopales de esta década, lo que debe verse allí es una línea de continuidad atravesada por una inquietud fundamental, la relación Iglesia-mundo, si bien en un movimiento que va desde una visión intraeclesial a otra más centrada en la misión de la Iglesia en el mundo, entendida bajo una luz de renovación ${ }^{10}$. Los grandes desafíos mueven así a los obispos a centrar su reflexión en la necesidad apremiante de forjar una espiritualidad renovada ante los tiempos que corren, en una perspectiva capaz de iluminar la conciencia cristiana acerca de la tarea

6 El cristiano de hoy, el mundo actual y los medios de difusión, Santiago, julio 1962, Cap. I, nn. 2 y 3.

7 Circular al clero..., abril 1963.

8 La Iglesia y el problema del campesinado chileno, Santiago, marzo (cuaresma) 1962.

9 Sobre este tema, cf. mi artículo «Manuel Larraín y la conciencia eclesial latinoamericana. Visión y legado de un precursor», Teología y Vida, Vol. L/1-2 (2009) 13-40, esp. 24-30.

10 Este cambio de perspectiva se puede notar ya en la «Circular que envían los Obispos de Chile desde Roma», noviembre 1965: «El Papa llama al mundo a concluir el Concilio en una gran oración "de modo que la Iglesia entera en estos días, en todas las partes del mundo, esté unida en fervorosa plegaria con los sucesores de Pedro y de los Apóstoles, como lo estuvieron los primeros Apóstoles alrededor de María, Madre de Jesús, y nuestra, en el Cenáculo, para implorar una nueva Pentecostés que renueve, por la Obra del Espíritu santo, el rostro de la Esposa de Cristo y de la Sociedad" (Exhortación)». El destacado es mío. 
de cambiar el mundo no al margen, sino junto con el cambio de lo más profundo de las personas por la evangelización ${ }^{11}$.

En esta misma línea, hacia finales de la década ya está instalada, sobre todo gracias a la inspiración del Concilio Vaticano II, la terminología de los «signos de los tiempos»" ${ }^{12}$ y una eclesiología en que las comunidades eclesiales de base llegan a ser consideradas con un status de prioridad ${ }^{13}$, aunque ciertamente sin que ello implique que la estructura de jurisdicción tradicional de la parroquia haya perdido su razón de ser. Una declaración posterior destaca el hecho de que una asamblea plenaria celebrada en Chillán en 1968 supo anticipar, precisamente con su aliento a las comunidades cristianas de base, el espíritu que predominaría en la segunda Conferencia General del Episcopado Latinoamericano en Medellín ${ }^{14}$.

\subsection{La década de los setenta: al servicio de la reconciliación nacional}

La década de los setenta es, tras un período de ajuste y de "crisis de crecimiento» eclesial ${ }^{15}$, la década en que se desarrolla propiamente una primera fase del posconcilio. El gran tema es la profundización de la reflexión sobre relación Iglesia-mundo, en sus diversas derivaciones. A los temas ya mencionados al final de los sesenta, se suman ahora, sobre todo en los comienzos de la nueva década, otros más radicales, como la revolución, la liberación, el fenómeno de la politización de la Iglesia, la

11 Declaración de los obispos de Chile sobre problemas de la actualidad, Padre Hurtado, agosto 1969. Este es un aspecto que ya en la primera mitad del siglo había reflexionado el jesuita Alberto Hurtado; cf. S. FERNÁNDEZ, «¿Reformar al individuo o reformar la sociedad? Un punto central en el desarrollo cronológico del pensamiento social de San Alberto Hurtado", Teología y Vida, Vol. XLIX (2008) 515-544.

Orientaciones Pastorales II: comunidades cristianas de base, La Serena, junio 1969.

14 «La Conferencia Episcopal privilegiaba en Chillán (1968) la gran tarea que era edificar las Comunidades Cristianas de Base. Para esto trata de promover la Catequesis, la Liturgia y la vocación del laico comprometido. Todo esto sucedía antes que se celebrara la II Conferencia general del Episcopado Latinoamericano en Medellín, lo cual manifestaba el espíritu de vanguardia de la Iglesia chilena» (Introducción Orientaciones Pastorales I-II-III, Concepción, marzo 1970).

15 Los mismos obispos lo expresaron en su momento en términos muy semejantes: «Haciendo un juicio histórico podemos afirmar que precisamente estas Orientaciones inician un nuevo período para los grupos apostólicos y Movimientos. Señalan el término de la gran crisis (1965-68) y alientan ahora nuevas expresiones apostólicas que tienen en común el estar estructurados en Comunidades Cristianas de Base» (ibid.). 
relación entre cristianismo y "construcción de la historia», o dicho más en general: el rol del cristiano en los grandes procesos en que está embarcada la sociedad chilena ${ }^{16}$. También, por supuesto, el conflicto y la polarización que se observa entre los bandos políticos ${ }^{17}$.

Todo ello domina las preocupaciones de los obispos en el período que abarca la elección del gobierno de la Unidad Popular y los tres años que logró perdurar. La perspectiva de fondo en estas intervenciones es la apertura de los obispos a la idea de que los cristianos pueden y deben participar de los decisivos procesos de cambio y renovación que se viven en la sociedad chilena, pero evitando el sectarismo y la violencia, y sirviendo a la justicia sin olvidar que su base es la verdad; verdad a la que en esos momentos, según reprochan los pastores, los medios de comunicación no suelen servir ${ }^{18}$. En lo que respecta al clero, los obispos reiteran el principio de que sus miembros «se abstengan de tomar públicamente posiciones políticas partidistas», pues «lo contrario sería volver a un clericalismo ya superado y que nadie desea ver aparecer de nuevo»" ${ }^{19}$.

En 1973, el proyecto de la Escuela Nacional Unificada (ENU) destaca como una gran preocupación de los obispos chilenos, y en consecuencia ocupa un especial lugar en sus intervenciones la defensa de la libertad de educación ${ }^{20}$.

A partir de ese mismo año y de un modo especial desde 1974, un gran concepto que se agregará al mensaje de los obispos será el de la reconciliación. Es indudable que ello responde a la situación de violen-

16 Declaración de los obispos chilenos sobre la situación actual del pais y Carta de los obispos de Chile a los Consejos de Presbiterio y a los superiores de congregaciones religiosas, ambos de la Asamblea Plenaria extraordinaria, Punta de Tralca, septiembre 1970; El evangelio exige comprometerse en profundas y urgentes renovaciones sociales, abril 1971; Por un camino de esperanza y alegría, Punta de Tralca, abril 1972.

17 Cf. La misión de la Iglesia en el Chile de hoy y el quehacer del obispo en la conducción pastoral de esta Iglesia, Punta de Tralca, diciembre 1972 (con especial alusión al gran "paro de octubre» en contra del gobierno de la Unidad Popular); Mensaje de Resurrección de los obispos de Chile, Punta de Tralca, abril 1973.

18 Por un camino..., 5.

19 El Evangelio exige..., Punta de Tralca, abril 1972, en alusión a una «declaración de un grupo de sacerdotes, publicada y comentada últimamente en los medios de comunicación social» (n. 10).

20 Declaración de la Asamblea Plenaria del Episcopado sobre la Escuela Nacional Unificada, Punta de Tralca, 11 abril 1973. 
Cien declaraciones de las Asambleas Plenarias del Episcopado Chileno (1962-2010): | 701

cia institucionalizada y de terror impuesta por el aparato de represión política del régimen militar a partir de la fuerte polarización ideológica que había culminado en el golpe de Estado del 11 de septiembre de 1973. Llama la atención que el documento La reconciliación en Chile, de abril de 1974, trasunta una actitud bastante positiva hacia el nuevo régimen $^{21}$, y en cambio una visión muy crítica del gobierno anterior y sus partidarios $^{22}$. Pero ya en la misma declaración los obispos manifiestan su preocupación por el «clima de inseguridad y temor» y por situaciones tales como los despidos por razones políticas y la falta de resguardos jurídicos eficaces para la seguridad personal ${ }^{23}$. Estas preocupaciones se irán agudizando en los años siguientes y, como se sabe, se expresará en una acción decidida de la Iglesia en la defensa de los derechos humanos ${ }^{24}$.

\subsection{La década de los ochenta y el llamado permanente a la solidaridad}

La década de los ochenta comienza con el acontecimiento del plebiscito por el que finalmente se aprobó la nueva Constitución Política (1980),

21 «Nuestros Gobernantes, informados del contenido de la presente Declaración, han tenido la noble actitud de respetar en todo nuestra libertad, lo que constituye la mejor prueba del derecho a disentir que existe en Chile, y de la vigencia del derecho en nuestra Patria» (presentación de la declaración La reconciliación en Chile, Santiago, abril 1974, 4).

22 «Porque hemos debido tocar temas delicados, queremos advertir, sobre todo a los extranjeros, que la situación chilena es incomprensible si no se tiene en cuenta el estado caótico y de enorme exacerbación pasional que existió durante el Gobierno anterior. Tampoco se puede entender la situación actual si no se tiene en cuenta la resistencia armada que aún ahora subsiste de parte de algunos políticos contrarios al actual gobierno; resistencia que nos parece del todo inútil e inmensamente dañina para nuestra Patria y para muchas personas que vienen a ser las víctimas de las pasiones políticas descontroladas».

«Finalmente, queremos hacer presente, a quienes lean esta Declaración en el extranjero, que ella refleja una situación que atañe solo a los chilenos (...) y no deseamos por ningún motivo que personas extrañas a nuestra Patria no respeten nuestra independencia, mezclándose indebidamente en nuestros asuntos...” (ibid., 5).

Cf. ibid., 4.

24 Un ejemplo eminente es el Mensaje de Navidad, San José de la Mariquina, diciembre de 1975, en que los obispos chilenos solicitan derechamente al gobierno militar «la concesión de una generosa amnistía a los detenidos políticos que pudieran acogerse a ella por la falta de méritos suficientes, por el tiempo prolongado de su detención sin haber sido sometidos a proceso o por la urgencia de volver a ocupar el vacío que dejaron en sus familias». 
incluidos sus polémicos artículos transitorios. Los obispos se refieren a este proceso poniendo acento en las condiciones que deben asegurar su legitimidad, pero también denunciando ciertas circunstancias que no son compatibles con tales condiciones ${ }^{25}$.

Luego, en los comienzos de esa década, tras una fugaz y poco consistente bonanza económica, adviene una severa recesión. A la noción de reconciliación, ahora los obispos sumarán otra que llegará a estar en el centro de todo un programa de acción de la Iglesia: la solidaridad. En efecto, este será el gran valor promovido por los pastores en esta década. Ante la pobreza de muchos, ¿qué corresponde? En primer lugar, la solidaridad, es decir, compartir de algún modo la suerte de los que más sufren, y no contentarse con limosnas o dádivas, por lo general también ocasionales. La solidaridad se transforma así en una expresión concreta y privilegiada de la reconciliación. Frente a la miseria de muchos, la invitación a los chilenos es a reencontrarse como hermanos en acciones solidarias ${ }^{26}$.

A partir del documento El renacer de Chile, de 1982, este mensaje fundamental de los pastores va a ir haciéndose cada vez más sólido y persistente. Se enfrenta la crisis en sus diversas dimensiones (económica, sobre todo por la cesantía; institucional por la lesión a los derechos humanos, etc.), como una oportunidad para reencontrarse como pueblo y tomar una nueva dirección ${ }^{27}$. La palabra de los obispos ya es, por momentos, muy severa y a veces muy explícita, como en La lección de pesebre, de diciembre de 1983, donde se habla derechamente de los torturados, de la Central Nacional de Información (CNI) y del exilio ${ }^{28}$. En mayo de 1984 los obispos dicen: Nunca perderemos la esperanza y hacen un llamado a los gobernantes a que hagan «un gran gesto» en favor de la reconciliación nacional.

En esta misma perspectiva pastoral abordan los obispos la significación fundamental de la visita del papa Juan Pablo II a Chile en 1987. La presencia del sucesor de Pedro entre nosotros es esperada por los

25 Declaración sobre el plebiscito, Santiago, 23 agosto 1980.

26 Declaración (ante la recesión), Santiago, 21 diciembre 1981; Llamados a compartir, Santiago, julio 1982.

27 Cf. Un nuevo llamado (con ocasión de la cuarta "protesta nacional"), Santiago, agosto 1983.

28 Cf. también Reconciliación en la verdad, Asamblea Plenaria Extraordinaria, sin indicación de lugar, junio 1985; Justicia o violencia, Santiago, abril 1986. 
pastores como un incentivo apremiante a la reconciliación en la verdad y en la justicia, es decir, como una invitación a preparar para el visitante ilustre una casa renovada y no meramente blanqueada en la superficie. Concretamente, el camino a la justicia se debe iniciar por un acto de solidaridad con los que han sufrido la injusticia:

«El viene a confirmarnos en la fe y a renovar nuestra esperanza (...) Como la suya, nuestra misión es anunciar la Buena Noticia de Jesús, el Señor Resucitado, y recordar los valores morales que se derivan del Evangelio y que deben inspirar la vida (...) Hacemos nuestras las angustias y esperanzas de todos. Oímos el clamor por la justicia y contra la violencia y este es tan fuerte y general que "si nosotros calláramos, las piedras hablarían" y "el Señor nos llamaría malos pastores" (...) Esperamos que se haga justicia plena en relación a quienes han desaparecido, han sido asesinados, maltratados e incluso degollados. No es suficiente afirmar que la justicia tarda pero llega. La justicia que no se ejerce cuando corresponde ya es injusta. Deteriora la convivencia social. No responde a los requerimientos de los afectados ${ }^{29}$.

Del mismo modo, la reflexión a que invitan los obispos tras la visita del Papa se orienta a «recoger sus enseñanzas y concretarlas en nuestra vida personal y social». Y, precisamente, el primer llamado es a la reconciliación nacional, «que no admite demoras» y que exige prontas concreciones en los planos político y socioeconómico ${ }^{30}$.

Al acercarse el final de la década, es decidido el compromiso de la conferencia episcopal con un rol orientador de los fieles y de la sociedad chilena en su conjunto hacia la recuperación de la democracia por la vía pacífica $^{31}$, y en especial por una participación responsable en el plebiscito del sí o el $n o^{32}$ y en los siguientes procesos eleccionarios ${ }^{33}$.

29 Justicia o violencia, Santiago, abril 1986. En la misma línea, el Mensaje de los Obispos al pueblo de Chile, Santiago, diciembre 1986, invita a preparar la visita del Santo Padre en una actitud de conversión, arrepentimiento y reconciliación.

30 El desafio de la reconciliación, Asamblea Plenaria extraordinaria, Santiago, mayo 1987.

31 Cf. Por una transición en paz, Asamblea Plenaria extraordinaria, Lo Cañas, Santiago, abril 1989.

32 Cf. En justicia y paz, Santiago, abril 1988.

33 Cf. Democracia en paz, Punta de Tralca, diciembre 1989. 
1.4 La década de los noventa: la Iglesia en la transición a la democracia

En los noventa las declaraciones constituyen un notable aporte a la gran tarea nacional, que es ahora la transición a la democracia. Se ve claro que un acto electoral, por más significativo que sea, no logrará por sí solo ese objetivo, sino que será un proceso que llevará su tiempo. Con una mirada positiva, los obispos se reconocen en ese contexto como "testigos de una clara voluntad de diálogo» ${ }^{34}$ en los diversos actores sociales, pese a la lamentable persistencia de «hechos de violencia fraticida, de terrorismo y delincuencia ${ }^{35}$. Ello indica que todavía hay heridas que sanar. Por lo mismo, la Comisión Verdad y Reconciliación tiene para los obispos chilenos un valor más que simbólico ${ }^{36}$. A través de la década, las declaraciones de las Asambleas Plenarias acompañan muy de cerca todos estos delicados procesos ${ }^{37}$.

Al mismo tiempo, ya establecida la democracia y vueltos a sus cauces normales muchas funciones que la misma Iglesia había cumplido subsidiariamente durante los años del régimen militar, pero sobre todo en un nuevo marco de cultura política, comienza a asomar, con una intensidad especial, la preocupación de la jerarquía de la Iglesia chilena por el tema de la familia, sobre todo porque ya se ve venir la discusión de una ley de divorcio ${ }^{38}$. Esta temática comenzará a aparecer en forma creciente en

34 Ven, Señor Jesús, Punta de Tralca, noviembre 1990, 4.

35 Ibid., 5.

36 Ibid., 6.

37 Cf. v. gr. En una etapa nueva del pais, La Serena, abril 1990; Esperanza y reconciliación, Punta de Tralca, noviembre 1998; Frente a nuestro deber cívico, Punta de Tralca, noviembre 1999.

38 Comunicado sobre la 66 Asamblea Plenaria, Punta de Tralca (pero extendido en Santiago), noviembre 1991. En ella y como preparación al Año Internacional de la Familia (1994), los obispos se refieren a los «enormes desafíos» a que se enfrenta esta institución fundamental, debido a «los embates de una sociedad consumista y permisiva, y débil en valores trascendentes». En el Comunicado de la Asamblea Plenaria, Punta de Tralca, abril 1994, 4 y 5 se dice: «Respecto a la eventual aprobación en el Parlamento de una ley de divorcio con disolución de vínculo, reiteramos la doctrina tradicional de la Iglesia sobre la indisolubilidad del matrimonio, proveniente de la naturaleza misma de la alianza conyugal. Alentamos la elaboración de un Código de la Familia que busque fortalecerla, sin dejar de atender los casos dolorosos de ruptura...». Cf. también Por el bien de las familias de Chile, Punta de Tralca, abril 1994. 
los comunicados y declaraciones de las Asambleas Plenarias ${ }^{39}$. A ella se sumarán desde ahora, y con especial intensidad, otras preocupaciones de índole sociocultural, tales como la educación, las clases de religión en la educación primaria y secundaria ${ }^{40}$ y la problemática de las drogas ${ }^{41}$. Esta inquietud fundamental por el grado de influjo del cristianismo en los procesos culturales denota la sintonía de la reflexión de los obispos chilenos con el tema central de la cuarta Conferencia General del Episcopado Latinoamericano, que se realizaría en Santo Domingo en $1992^{42}$.

También destacable en la segunda mitad de los noventa es la intensificación del tema del rol de los laicos en la Iglesia y en el mundo. Se toca varias veces y en diversas ocasiones se invita a laicos que expongan temas de importancia en las Asambleas Plenarias. Esto tiene relación con el nuevo marco social y político, propio de la normalidad de un sistema democrático, en que es el laicado el que está en las líneas importantes del quehacer nacional.

Por esta época aparecen asimismo las primeras menciones especiales a la problemática indígena. Ya en 1991 el comunicado de la 62a Asamblea Plenaria tocó el tema y habló, derechamente, de las «legítimas aspiraciones de dichos grupos étnicos» ${ }^{43}$. En el documento Resolvamos los conflictos con los pueblos indígenas, de mayo de 1999, es de notar la perspectiva adoptada por los obispos. El contexto está dado por los conflictos entre mapuches y empresas forestales, que habían seguido a los ocurridos poco antes entre pehuenches y la hidroeléctrica Ralco, en el Alto Biobío. Reiterando su llamado al diálogo, los obispos ponen el siguiente acento:

39 Cf. especialmente Comunicado de prensa de la $74^{a}$ Asamblea Plenaria, La Florida, Santiago, noviembre de 1997 (sobre el proyecto de ley sobre el divorcio vincular); Frente a nuestro deber cívico, Punta de Tralca, noviembre 1999, 4.7: "Necesitamos gobernantes y legisladores que impulsen políticas que favorezcan la constitución de familias que sean verdaderos santuarios de la vida y de la paz, familias estables, en las cuales se valore a los hijos, y haya diálogo, complementariedad y fidelidad».

40 Cf. v. gr. Comunicado de la 68 a Asamblea Plenaria, Valdivia, noviembre 1994.

41 "No nos ha llamado Dios a la inmundicia sino a la santidad" (1Tes 4,7), Punta de Tralca, mayo 1995. Cf. también el Comunicado de prensa de la $71^{a}$ Asamblea Plenaria, Punta de Tralca, abril 1996. Cf. también Comunicado de la $71^{a}$ Asamblea Plenaria, Punta de Tralca, abril 1996.

42 Cf. Comunicado de la 62a Asamblea Plenaria, Santiago, noviembre 1991, 2.

43 Ibid., 7. 
«Para el pueblo mapuche la tierra tiene una honda significación para su vida. La valoración de ella no es principalmente económica, sino como el espacio otorgado por Dios para su desarrollo. Todos los chilenos debemos reconocer el derecho a una digna existencia al millón de connacionales pertenecientes a diferentes etnias originarias. Y colaborar para que no solo las leyes les reconozcan su condición de pueblos de culturas distintas, sino que puedan sentir y experimentar con orgullo su propia identidad, tanto los que viven en el campo como en la ciudad. Con el aprecio, el afecto y los vínculos mutuos se crea ese espacio de fraternidad que llamamos Chile» ${ }^{44}$.

Desde este reconocimiento básico, los obispos instan a que prontamente se encuentren

«caminos más ágiles de aplicación de la Ley Indígena para resolver los problemas de fondo... (sobre todo) la capacitación para el verdadero desarrollo social... que, con respeto a las propias culturas, les permita enriquecerse con los conocimientos y las técnicas del mundo moderno, y pueda resolverse la grave pobreza en la cual hoy se encuentran tales comunidades $»^{45}$.

Para los pastores, la búsqueda del progreso socioeconómico y, antes, de la superación de la pobreza, no debe ser entendida como un objetivo incompatible con el respeto de la identidad cultural y con el reconocimiento de las reivindicaciones históricas de los pueblos originarios. Por eso mismo, denotan en sus intervenciones la complejidad del tema de fondo de toda esta problemática. En definitiva, debería aplicarse aquí lo dicho por ellos un año antes:

«... más allá de los procesos judiciales, es nuestra cultura la que debe incorporar de manera más profunda y plena el trato que se merece todo ser humano, por su dignidad como persona y como creatura e hijo de Dios. El respeto a la vida -del que es más débil, del enfermo, del encarcelado, del enemigo, del anciano y del que aún no ha nacido- debe ser la base de nuestra convivencia» ${ }^{4}$.

\footnotetext{
44 Resolvamos los conflictos con los pueblos indígenas, Punta de Tralca, mayo 1999, 3.

45 Ibid., 6.

46 Esperanza y reconciliación, Punta de Tralca, noviembre 1998, 9. El destacado está en el original.
} 
1.5. A partir del 2000: la voz de los obispos en una sociedad más secularizada y plural

La década de los 2000 comienza, como es lógico, con la reflexión en torno al jubileo. Un concepto emergente es aquí el perdón que pide la Iglesia, siguiendo al papa Juan Pablo II, por los pecados que ella ha cometido en esta larga historia ${ }^{47}$. Siguiendo la inspiración bíblica, se le da una especial importancia a la dimensión social del jubileo, y el enfoque en este punto sigue siendo el de una invitación a la solidaridad, es decir, a una actitud permanente de empatía y de compartir con los más desposeídos, y no solo a acciones puntuales de beneficencia. Por eso tienen un lugar importante en las reflexiones de las Asambleas Plenarias de este período temas como la falta de trabajo ${ }^{48}$ y las iniciativas que combaten el individualismo y promueven una actitud duradera y comprometida de solidaridad con los más pobres. Se destacan como una verdadera luz de esperanza la campaña por la construcción de mediaguas para el gran jubileo y el crecimiento del voluntariado de jóvenes, y junto con ello los obispos siguen alentando en general a una vida más austera como expresión concreta y a la vez más permanente de solidaridad con los que menos tienen ${ }^{49}$.

Paralelamente, sigue siendo importante en la agenda de las Asambleas Plenarias, debido sobre todo a los avances en la legislación sobre el divorcio, la doctrina católica sobre la familia ${ }^{50}$.

Los escándalos sexuales y los casos de abusos de esta índole por parte de miembros del clero en diversos lugares del mundo, que llevan a cuestionar con especial fuerza en la opinión pública la institución del celibato, también obligan a los obispos a manifestarse. Estos temas dejan de manifiesto, de manera cada vez más clara, que la Iglesia experimenta el desafío fundamental de aprender a vivir en una sociedad que pide cuentas a la institución eclesial, sin mayores consideraciones, incluso en

\footnotetext{
Informe de prensa sobre la 79a Asamblea Plenaria, Punta de Tralca, mayo 2000.

48 Informe de prensa sobre la 80a Asamblea Plenaria, Punta de Tralca, noviembre 2000.

49 Reanimar la solidaridad y la esperanza, Punta de Tralca, mayo 2001.

50 Busquemos el bien de la vida familiar y de sus hijos, Punta de Tralca, noviembre 2001; Declaración sobre proyecto de Ley de Matrimonio Civil, Punta de Tralca, mayo 2002. Luego, el tema será abordado en diversas asambleas plenarias, como un tema de fondo y de permanente actualidad.
} 
cuestiones propias de su vida interna, en la medida en que persiste la sospecha de que ellas pueden estar incidiendo en la comisión de delitos, o al menos en actitudes impropias que afectan a la sociedad en su conjunto. Frente a ellos, ya a comienzos de la década, en mayo de 2002, la respuesta colegiada de los obispos chilenos es clara. Siguiendo a Juan Pablo II, dicen: "no hay lugar en el sacerdocio y en la vida religiosa para quienes dañan a los jóvenes»; y en coherencia con ello se comprometen a «seguir cuidando con esmero, con la asesoría de especialistas, los procesos de selección y admisión de los candidatos al ministerio sagrado y a la vida religiosa, como también los planes y programas de formación inicial y permanente de nuestros sacerdotes, diáconos y personal consagrado ${ }^{51}$. En noviembre de ese mismo año, los obispos explicitan un compromiso decisivo, fuertemente esperado por el pueblo de Dios y por la opinión pública en general:

«...queremos colaborar con toda transparencia en los procesos judiciales ante los tribunales civiles, sin pedir un trato diferente al estipulado por la ley, y sin que se obstruya en nada el ejercicio de la justicia, ${ }^{52}$.

En cuanto al contexto histórico, dos acontecimientos merecen una especial atención en las declaraciones de este período: la canonización del P. Alberto Hurtado, S.J. y la preparación y luego las repercusiones de la Quinta Conferencia General del Episcopado Latinoamericano en Aparecida (2007). Los mensajes que se refieren a lo primero, destacan la fuerza inspiradora del jesuita para los cristianos de Chile y del mundo de hoy, pero se subraya su significación en el ámbito de la conciencia y del apostolado en lo social ${ }^{53}$. En cuanto al tema de Aparecida, se destaca la amplia participación eclesial en su preparación, en un clima de intensa comunión, pero no se observa una reflexión detenida, al menos no explícitamente, sobre el significado eclesiológico de la invitación de la Conferencia a ser una Iglesia de «discípulos misioneros» en esta hora de Latinoamérica.

51 Declaración sobre abusos sexuales, Punta de Tralca, mayo 2002.

52 Una voz de alerta y un llamado apremiante, Punta de Tralca, noviembre 2002. El tema reaparece en Reconstruir desde Cristo la 'mesa para todos', Punta de Tralca, abril 2010, en el contexto de nuevos casos de escándalos sexuales en la Iglesia, la reciente carta del papa Benedicto XVI a la Iglesia irlandesa y otros casos.

53 Cf. v. gr., Para la vida de Chile, Padre Hurtado, abril 2004, 4; Navidad, en una familia..., Punta de Tralca, noviembre 2005. 
En el transcurso de esta década se observa, en general, en las declaraciones la búsqueda de una síntesis más acabada en torno al mensaje sobre la persona y su dignidad, la cual debe basarse en una sólida moral de la vida a la par de una clara ética social. Lo primero aparece, es cierto, debido sobre todo al contexto social y cultural, especialmente ligado a las temáticas relacionadas con el matrimonio y el comienzo de la vida humana (por ejemplo, la polémica por la así llamada "píldora del día después»); lo segundo, en relación a las exigencias de una cultura política con un camino ya recorrido, a los peligros de la corrupción y a otros «asuntos pendientes» de gran importancia social: la reforma previsional ya aprobada, las reformas legislativas sobre educación y los esperados aportes del Consejo Asesor Presidencial de Equidad y Trabajo ${ }^{54}$.

Este esfuerzo de aproximación más equilibrada al tema central de la dignidad humana, que salta a la vista mediante una lectura atenta de las declaraciones de este período ${ }^{55}$, impulsa a matizar la opinión, muchas veces escuchada, de que los obispos chilenos habrían debilitado, tras el retorno a la democracia, la dimensión social del mensaje cristiano, para centrarse en los temas relacionados con la moral sexual, de la familia y de los comienzos de la vida. Innegablemente hay una evolución de los acentos en este sentido entre las declaraciones de las décadas de los setenta y de los ochenta, y las de los noventa en adelante. La explicación de este hecho remite a diversos factores relacionados con los cambios en el contexto en que se ha inscrito la labor de la Iglesia en la sociedad chilena y también, paralelamente, a las políticas y los criterios intraeclesiales que han predominado en tales procesos. Es claro, por de pronto, que la Iglesia Católica evaluó su accionar en las décadas precedentes como el ejercicio de una función subsidiaria en un contexto político y social de excepción, por lo que, acontecido el retorno a la democracia, correspondía retomar más claramente el rol eclesial propio, que, según esta perspectiva, es la evangelización en un sentido religioso más explícito. El

54 Cf. especialmente La persona y su dignidad, base de nuestra convivencia, Punta de Tralca, abril 2008.

55 Cf. v. gr., Crónica de la 88a Asamblea Plenaria, Punta de Tralca, noviembre 2004 (en que la globalización y el proyecto de una Carta a las Familias conviven en el centro de la agenda del encuentro); Navidad, en una familia viene la luz al mundo, Punta de Tralca, noviembre 2005 (ante el nuevo gobierno, la preocupación de la Iglesia es doble: la inequidad social y el debilitamiento de la institución de la familia); Vida nueva en Cristo, Punta de Tralca, abril 2006, etc. 
perfil predominante en los nombramientos de obispos en este período, sería un reflejo de este criterio. Lo del carácter subsidiario de las funciones eclesiales aludidas es discutible desde el punto de vista de la cuestión del sentido de la presencia de la Iglesia en medio de la humanidad y su historia. Pero en todo caso, también es preciso hacer notar que el tema de la dimensión social de la fe nunca deja de estar presente en los mensajes de las Asambleas Plenarias ${ }^{56}$ y, como se ha dicho antes, aparece con una claridad aun mayor en la mencionada búsqueda de un mensaje más equilibrado sobre la concepción cristiana de la dignidad de la persona, en su doble dimensión individual y social.

\section{PrinCiPAles Claves TeOlÓGICAS}

Luego de esta visión de conjunto, quisiera invitar en lo que sigue a un intento de identificación de algunas claves teológicas importantes en la mirada de los obispos sobre la realidad en la que se ha inscrito la vida del pueblo de Dios en estos decenios. ¿Qué perspectivas teológicas habría que destacar? ¿Cuáles han sido constantes en su aproximación pastoral? Sugiero cuatro, consciente de que pueden ser más, a partir de otras miradas.

\subsection{La intuición básica de una teología de los signos de los tiempos}

Me parece que esta intuición, formulada aquí con una terminología posterior que no estuvo explícitamente en las primeras declaraciones, es sin embargo clara y decisiva. Si nos preguntamos acerca de la razón última de este enfrentar «la realidad» por parte de los obispos a la luz del Evangelio, me parece que esa razón es la convicción de que lo que acontece constituye siempre una potencial interpelación del Dios de Jesucristo o un soplo del Espíritu que es necesario discernir, para cumplir Su voluntad en cada momento. En otras palabras, lo que estaría en el origen mismo de toda esta historia de pronunciamientos pastorales es una suerte de anticipo de aquello que diría el Concilio Vaticano II en la Constitución Gaudium et spes, n. 4:

«es deber permanente de la Iglesia escrutar a fondo los signos de los tiempos e interpretarlos a la luz del Evangelio, de forma que, acomodándose a cada generación, pueda la Iglesia responder a los perennes interro-

56 El mensaje más explícito al respecto en este período es $A$ despertar la conciencia moral y social, Punta de Tralca, noviembre 2006. 
gantes de la humanidad sobre el sentido de la vida presente y de la vida futura y sobre la mutua relación de ambas» ${ }^{57}$.

La pregunta de fondo que se planteó desde ese inicio y en adelante es: ¿qué significa la historia para la fe cristiana? En ello habría que considerar, en actitud de reconocimiento agradecido, el rol precursor de hombres y mujeres de la Iglesia chilena que, a lo largo de toda su historia y de un modo especialmente intenso en la primera mitad del siglo XX, supieron asumir el desafío de releer la misión de la Iglesia en el contexto del acontecer histórico del mundo moderno. Pensemos, ante todo, en el P. Fernando Vives, S.J. y en sus discípulos Manuel Larraín y Alberto Hurtado, pero también tantos otros cristianos, laicos y religiosos anónimos, que supieron tomar compromisos concretos para hacer de Chile una nación más abierta al ideal del Evangelio.

2.2. La dimensión práctica y social como aspecto esencial de la fe cristiana en cuanto fe histórica

Esto, que aparece como una concreción de lo anterior, no podemos considerarlo tampoco como algo obvio. Es, en realidad, fruto de un esfuerzo constante de la Iglesia en contra de la tentación, igualmente persistente, a la privatización de la fe. Esta ha sido una tendencia presente en aquella forma de religión que en su momento Marx criticó como «opio del pueblo», por su rol -en ese momento, a decir verdad, difícilmente negable- de legitimación ideológica de un orden social injusto. Pero también ha estado presente en las perspectivas modernas liberales y secularistas que, en diversas versiones, han buscado interesadamente arrinconar al cristianismo en el ámbito de lo privado, esto es, en una localización en que no le fuera en absoluto factible su legítima pretensión de contribuir con sus ideales en el ordenamiento de la polis y, más exactamente, en el orden social.

Una Iglesia que, a través de la voz de sus pastores, ha perseverado en decir una palabra orientadora para la praxis cristiana en la existencia y en la coexistencia social en sus diversas dimensiones, debe ser valorada, a mi juicio, como testigo de una fe que, si bien no se reduce a una ética, no puede renunciar a ella en cuanto expresión concreta de la experiencia de la salvación en Jesucristo, el Hijo de Dios que se ha hecho hombre

57 Los destacados son míos. 
entre los hombres para hacernos partícipes de la vida divina. Otro asunto, aunque estrechamente ligado a este aspecto, ha sido la forma concreta de entender la articulación histórica de esta implicancia existencial cristiana en la sociedad. Ya volveremos a este punto.

En cuanto a la relación ya aludida entre la dimensión individual y la dimensión social del concepto cristiano católico de la salvación, ya se ha dicho algo en las páginas precedentes. De cualquier forma, es necesario hacerse cargo de la percepción que ha predominado en la opinión pública e incluso al interior del pueblo de Dios, acerca de un eventual enfriamiento del ímpetu social del mensaje de la Conferencia Episcopal chilena. Aceptada la necesidad de matizar tal juicio considerando el testimonio de las declaraciones aquí estudiadas, es preciso también reconocer un cierto desplazamiento de los acentos. Habría que agregar que ello debe ser considerado en el contexto más amplio de los procesos históricos experimentados por el conjunto de la sociedad chilena, en la cual y para la cual existe la Iglesia. Es decir, no solo esta sino también aquella ha evolucionado -y muy comprensiblemente- hacia un nuevo escenario, el escenario de una sociedad en pleno ejercicio de la democracia y en un ambiente de creciente pluralismo, no solo político sino también cultural en sentido amplio. Si a ello se agrega el hecho de que muchas funciones que cumplió la institución eclesial durante los años del régimen militar luego fueron reasumidas por las diversas instancias y estructuras de una sociedad democráticamente organizada, es comprensible que se haya establecido un nuevo ordenamiento de los actores sociales y sus roles. Pero en ese contexto no ha carecido de complejidad y de cierta indefinición la forma concreta de entender las competencias y las pretensiones propias de la Iglesia Católica en la sociedad chilena. Ante el peligro de una Iglesia excesivamente comprometida en asuntos propios de las autoridades políticas y técnicas -que se ha criticado bien como clericalismo, bien como un intento de hegemonía cultural indebida-, es innegable que se ha tendido también, por momentos y en especial en ciertos sectores del catolicismo, a una privatización de la fe y a una distorsionada espiritualización del cristianismo, como si la solicitudo rei socialis fuera una cuestión del pasado, un asunto ya superado, y no una dimensión esencial del seguimiento de Jesús hoy. En esa tensión ha tenido que avanzar la palabra de los obispos chilenos desde el retorno a la democracia, en el seno de una sociedad crecientemente integrada al mundo global y a la cultura del pluralismo. 
2.3. La dimensión eclesial de una teología de los signos de los tiempos

El discernimiento de los llamados de Dios en el acontecer histórico y social aparece, en las declaraciones de las Asambleas Plenarias, como un desafío ante todo para la Iglesia como un todo y no meramente para los cristianos individualmente considerados. Queda también claro que cada uno de los cristianos estamos llamados a ese discernimiento, en una vivencia adulta y responsable de la fe. Pero es necesario que ese conjunto de discernimientos personales se inscriba en la Iglesia, pueblo de Dios, como el espacio propio de la búsqueda permanente de la voluntad de Dios y como comunidad de fe necesaria para la salvación en cuanto acontecimiento histórico.

En esta dimensión, la palabra de los obispos a través de las declaraciones de las Asambleas Plenarias, ha jugado un rol claramente eclesial, tanto por ser una voz autorizada de la Iglesia ante el conjunto de la sociedad, como también por el esfuerzo contenido en ellas de incorporar el sentir y las búsquedas de la comunidad eclesial toda. Luego insistiré en un aspecto importantísimo implicado en lo que estoy diciendo, esto es, la relación que existe entre la función magisterial orientadora de los pastores y el sensus fidelium. La voz de los obispos no solo orienta a la comunidad, sino que también, y con anterioridad, la representa.

Otro aspecto importante de la dimensión eclesial del ejercicio teológico contenido en las declaraciones del episcopado reunido en Asambleas Plenarias, es el ejercicio de su rol pastoral en el contexto de la comunión. No solo en la comunión de las iglesias hermanas dentro de una nación o país, sino también de la comunión con la Iglesia universal, representada simbólicamente, en muchas ocasiones, por la participación del Nuncio Apostólico en los actos inaugurales de las Asambleas. Esto indica cuán importante ha sido el ejercicio concreto de la colegialidad episcopal, con dos implicancias concretas: en primer lugar, para la mayor unidad posible de criterios pastorales entre las diócesis chilenas; y en segundo lugar, ese esfuerzo en el contexto de una comunión más amplia, el de la Iglesia universal, que existe y se realiza concretamente en la vida de cada iglesia particular. La presencia del Nuncio ha significado así la comunión de la Iglesia chilena en su conjunto con el romano pontífice en cuanto articulador y garante de la comunión universal, y -en correspondencia- un gesto de compromiso y de confianza de este para con la Iglesia chilena y su quehacer. 
La suerte de los más pobres como criterio hermenéutico para una lectura pastoral de la realidad

La preocupación por la situación de los más pobres y por las repercusiones para ellos de los vaivenes de la vida social y política chilena, ha sido una constante que se puede constatar a primera vista en las declaraciones de las Asambleas Plenarias. Aplico aquí en sentido estricto la expresión "criterio hermenéutico» a esta preocupación del episcopado, porque efectivamente ha centrado la mirada pastoral y ha marcado así el sentido de la presencia y del actuar de la Iglesia en nuestra sociedad.

Si nos hacemos la pregunta: ¿por qué, en definitiva, han hablado los obispos chilenos sobre el acontecer social?, la respuesta inmediata es: para iluminar con la luz del Evangelio lo que a menudo ha estado lejos de esa luz. Pero en este punto surge un aspecto de la realidad social que resulta ineludible e innegable: que ante tales situaciones de oscuridad, los poderosos, los exitosos, han tenido herramientas de sobra para defenderse solos; pero no así los pobres, ni la gente común que vive de su trabajo y que es la que posibilita el funcionamiento de la sociedad. La voz de los pastores ha cumplido, en tales momentos, un rol iluminador, concientizador, de ayuda al reconocimiento de la dignidad personal de los más vulnerables. El principio rector de esta iluminación ha sido invariablemente el llamado a la solidaridad, esto es, a la empatía y al compromiso, como personas y como sociedad, con los que más sufren, y no meramente a la limosna generosa. Destacables han sido, en este sentido, los llamados -en tiempos de cuaresma, pero no solo en ellos- a la austeridad como una forma concreta y privilegiada de solidaridad con los que carecen de lo mínimo. Y en la misma línea, ha sido de especial importancia la referencia al ejemplo del P. Alberto Hurtado y su invitación a los cristianos a perfeccionar el sentido de la caridad con el sentido de la justicia.

\section{A MODO DE CONCLUSIÓN: PRINCIPALES DESAFÍOS}

Para terminar y a modo de una "conclusión abierta», es decir, en la línea de una reflexión que se proyecte en la tarea de seguir pensando a partir del mensaje de estas cinco décadas de Asambleas Plenarias, quisiera destacar algunas perspectivas eclesiológicas o desafíos que, a mi parecer, han quedado planteados para la Iglesia chilena toda, como un camino por recorrer. Destaco brevemente cinco: 
3.1. La relación estrecha de la voz de los obispos con el sensus fidelium

Ya he destacado este aspecto como parte de las claves teológicas de las declaraciones de las Asambleas Plenarias del episcopado. La voz de los pastores no solo ha sido una voz orientadora para el pueblo de Dios y en general para todos aquellos que han estado abiertos a escucharla, sino que también ha reflejado su enraizamiento en el sensus fidelium, de tal manera que ha sido también una voz que ha representado a la comunidad eclesial ante la sociedad. Los obispos no hablan en nombre de un estamento dentro de la Iglesia, como algunos todavía entienden la función magisterial de la jerarquía, sino en nombre de la Iglesia toda, el pueblo de Dios, en que el ministerio episcopal está radicado y para el cual tiene un sentido pastoral.

Esta concepción eclesiológica del sentido y del valor de las declaraciones de las Asambleas Plenarias del episcopado chileno se ha visto muchas veces refrendada por la metodología empleada en ellas y que se ha basado en la escucha de aportes y reflexiones de diversos representantes de la vida de la Iglesia, que han sido acogidos en las reuniones. Esta intuición me parece sumamente importante, porque es una concreción muy diáfana de la eclesiología del pueblo de Dios del Concilio Vaticano II. Tal vez, un paso adelante en esta misma dirección podría ser el esfuerzo por hacer de esos diálogos con los obispos acontecimientos todavía menos intraeclesiales, invitando a las Asambleas no solo a católicos convencidos y militantes, sino también a otros que, aunque más alejados de las estructuras de la Iglesia Católica, son bautizados y pueden representar, por ello, ante los pastores otras sensibilidades que también deben tener en cuenta en su aproximación a la realidad.

Por cierto, este desafío lleva implícita la compleja cuestión de la auténtica recepción del Magisterio en el conjunto del pueblo de Dios, auscultando de diversas maneras en qué medida las orientaciones de los pastores sobre diversos temas están siendo acogidas con disponibilidad, pero también en conciencia y con convicción, por parte del común de los fieles. Cuando los datos de la realidad indican una situación negativa al respecto, ello no debería ser pasado por alto. La relación entre Magisterio y sensus fidelium no es estática y, por lo mismo, desafía a una actitud eclesial permanente de apertura a un diálogo franco entre pastores y fieles. Este aspecto nos conecta con un segundo desafío de gran importancia. 
3.2. La necesidad de plantearse la pregunta acerca de las pretensiones de la Iglesia con respecto al orden social.

A este desafío ya aludí tangencialmente al referirme, como clave teológica de las declaraciones de las Asambleas Plenarias, a la afirmación de la dimensión práctica y social como elemento esencial a la fe. Al hacerlo, destaqué en qué sentido y en qué medida esa afirmación ha sido una contrapartida decisiva a los diversos intentos de privatización de la fe. Combatiendo esta tendencia, los obispos chilenos han sabido reivindicar el legítimo derecho de los cristianos a aportar, desde su inspiración específica, a la constitución del orden social.

Por otra parte, en esa reivindicación se ha reflejado una cuestión más de fondo, que tiene que ver con los modelos ideales subyacentes a la vinculación de cristianismo y sociedad. Es sabido que a lo largo del siglo $\mathrm{XX}$, con los impulsos del catolicismo social, del surgimiento de la Doctrina Social de la Iglesia y de movimientos teológicos de perspectiva más histórica y antropológica, como los que plantearon la polémica sobre el sobrenatural y, más tarde, la teología de las realidades terrestres, se fue dando al interior del pensamiento católico una superación de la actitud más bien apologética frente al mundo moderno que había predominado en los siglos recientes.

Ese proceso, que de alguna manera tuvo un momento de culmen en el Concilio Vaticano II, implicó para algunos sectores católicos importantes tener que ir asumiendo un inevitable distanciamiento del ideal tradicional de Cristiandad, para concebir nuevas formas de presencia cristiana en la sociedad moderna. La tendencia tal vez más representativa de esta reflexión había sido el así llamado proyecto de neocristiandad, inspirado en el pensamiento del filósofo francés Jacques Maritain y su apuesta por un "orden social cristiano» basado ya no en el protagonismo de la jerarquía eclesiástica, sino en el protagonismo de los laicos. Este ideal, que para algunos estaría a la base de la segunda encíclica social, Quadragesimo Anno del papa Pío XI (1931), introdujo en el catolicismo de la primera mitad del siglo XX una fuerte cuota de sentido de autonomía en la praxis social y política del laicado, si bien, obviamente, en una relación de fidelidad y subordinación a las directrices del Magisterio. En todo caso, se evolucionó, tal como lo describiera Alberto Hurtado en su libro Moral Social, a la distinción entre la "acción católica» y la «acción social temporal»; ambas protagonizadas por los católicos laicos, 
pero la primera ordenada a «bautizar este mundo» y la segunda a "construirlo sano, digno de su bautismo" ${ }^{58}$. Aunque, como sabemos, en Chile la «acción social temporal» creció pronto en su índole de autonomía, sobre todo en el plano político, de todos modos era todavía muy viva la pretensión de alcanzar un orden social explícitamente cristiano. Con el correr del siglo, esta pretensión ha tenido que ser repensada necesariamente, con el avance cultural de la secularización y la constitución de un modelo de sociedad caracterizado crecientemente por el pluralismo -no solo como hecho sino además como ideal-y, finalmente, por la laicidad. A partir de la separación de Iglesia y Estado sancionada en la Constitución Política de 1925, la Iglesia chilena ha debido enfrentarse al desafío creciente de ubicarse en este marco social y cultural de poscristiandad. Importantes temas que las Asambleas Plenarias han debido abordar, sobre todo a partir de la década del retorno a la democracia, así lo han demostrado.

Todo indica que lo que se ha manifestado en tales coyunturas es un proceso sin retorno que, por lo mismo, obliga a la Iglesia a plantearse preguntas de fondo: ¿qué hacer? ¿Cómo cumplir más fielmente en esta sociedad concreta la misión evangelizadora? ¿Bastará la reiteración voluntariosa de la doctrina asentada de la Iglesia universal sobre los más diversos temas? Me parece que estas preguntas no pueden responderse sencillamente con un sí o un no, sino que invitan a una reflexión más detenida y matizada. Pero una pista importante está presente en estas declaraciones de las Asambleas Plenarias y bien puede interpretarse como una formulación precursora de la intuición básica de la Conferencia de Aparecida. Es lo que señalo a continuación.

3.3. La voz de los obispos como testimonio de una Iglesia «comunidad de discípulos-misioneros» (Aparecida)

Esta voz de los obispos chilenos reunidos ha sido expresión de una búsqueda constante del sentido de la presencia cristiana en la sociedad y en la cultura. Y en este sentido, las futuras declaraciones de las Asambleas Plenarias deberían ser un testimonio importante de una Iglesia que quiere reencontrarse consigo misma como "comunidad de discípulos-misioneros». Lo que quiero decir con esto es que muy probablemente sea cada

A. Hurtado, Moral Social - Escritos inéditos, Vol. 3, Ed. por P. Miranda (Santiago 2004) 44 . 
vez más prioritario en la Iglesia chilena articular un espíritu misionero «desde dentro», es decir, que parta (ipero no termine!) por un trabajo de misión destinado a que los ya bautizados tomen conciencia de su dignidad y de su desafío bautismal, en un reencuentro profundo y adulto con la experiencia de la fe. El paso siguiente debería ser, en consecuencia, el redescubrimiento del sentido de la misión cristiana en el mundo y en la cultura de la poscristiandad.

Solo desde una tal experiencia cristiana y eclesial auténticamente adulta, podrá aspirarse a lograr una forma de presencia creyente en el mundo con solidez y credibilidad y, en consecuencia, con una mayor capacidad para entrar en interlocución con otros actores sociales y sus pretensiones de influir en la constitución del bien común. En complemento, será también necesario en las diversas formas de intervención de la jerarquía de la Iglesia un tono que, sin dejar de lado las convicciones de fondo, favorezca el diálogo y destaque la función antes constructiva que condenatoria de la Iglesia en el mundo.

3.4. Una comunidad de discípulos-misioneros que busca servir a la sociedad en la que está inserta

El sentido de la misión tiene que ser, pues, repensado seriamente y no solo como tarea para los teólogos, sino como cuestión de fondo de la identidad cristiana de cada creyente. ¿Qué es ser cristiano hoy? ¿Qué es ser Iglesia y qué le corresponde hacer como tal en esta sociedad que compartimos, cada vez más «de igual a igual», con otros?

Me parece cada vez más evidente que la preocupación básica de un nuevo impulso misionero no debe ser ya, como pudo serlo en un pasado no lejano, la recuperación de los altos niveles de influencia que tuvo la voz de la jerarquía eclesiástica en la sociedad tradicional de Cristiandad, sino mantener siempre vivo el ideal cristiano de una existencia y una coexistencia más humana y por eso mismo más de acuerdo al mensaje de Jesús. Dicho de otro modo, el pueblo de Dios esperará de sus obispos una palabra que ilumine por ser expresión de una Iglesia al servicio del Reino y de los preferidos de Jesús, los insignificantes del mundo, y no al servicio de sí misma o de sus privilegios en su dimensión institucional. Cada vez que la Iglesia se ha acercado a este ideal, ha crecido en credibilidad, y eso, creo, seguirá siendo así, y crecientemente, en el futuro. Ello se ha dado, por cierto, en muchos momentos, en un clima de inevitable 
conflicto con el poder en la sociedad, pero normalmente la jerarquía ha salido fortalecida ante los ojos del pueblo de Dios: tanto defendiendo la libertad de educación en el affaire ENU durante el gobierno de la Unidad Popular, como defendiendo el derecho y la dignidad de la vida de los perseguidos durante los años más duros del régimen militar.

\subsection{El compromiso con la defensa de la vida}

Una última perspectiva eclesial que quisiera destacar para el futuro, a partir de la lectura de las declaraciones de las Asambleas Plenarias, es el compromiso con la defensa de la vida humana desde su origen, en todo su transcurso y hasta el último instante, por el hecho de poseer una dignidad tal que no puede ser supeditada a ninguna otra consideración. Por esta convicción, a la Iglesia le ha importado y le seguirá importando todo lo humano y lo que lo construye, tanto en sus dimensiones individuales como en sus niveles sociales, políticos y culturales. Por eso la Iglesia, a través de sus pastores, puede y debe decir una palabra sobre todo esto, y de esa manera manifiesta su convicción de que el ser humano ha sido creado por Dios a su imagen $($ Gen 1,26$)$ y que en ello radica su dignidad: Gloria Dei, vivens homo, la gloria de Dios es el hombre que vive plenamente su calidad de tal. La palabra de los pastores, en estos cincuenta años, ha sido un esfuerzo constante por hacernos tomarlo en serio y por ayudarnos a discernir sus implicancias como pueblo, en una actitud activa, en el presente y en los nuevos desafíos que sin duda seguirán planteándose.

En su doble misión de iluminar las conciencias y de representar el sentir más profundo de los fieles, las cien primeras declaraciones de la Asambleas Plenarias del episcopado chileno deben ser leídas como testimonios no solo del mensaje de los obispos de esta nación en un determinado segmento histórico, sino también de la Iglesia toda que ellos han guiado en una compleja combinación de búsqueda de la verdad, de empeño por servir a la patria a la luz del Evangelio y, también, de no pocos momentos de perplejidad. En otras palabras, testimonios del pueblo cristiano que está llamado todo él a discernir los llamados del Dios de Jesucristo y los signos de su reinado, en medio de la historia de nuestra patria. 
Resumen: En noviembre de 2010 se celebró la 100ª Asamblea Plenaria de la Conferencia Episcopal de Chile. Con ocasión de este simbólico acontecimiento, el presente texto ofrece los resultados de un estudio sobre el contenido de las declaraciones emanadas de estas asambleas episcopales. Primero se da una mirada histórica de conjunto a los textos, ordenados por décadas, para en un segundo momento destacar y analizar brevemente sus principales claves teológicas. Finalmente, a modo de conclusión, se reflexiona sobre algunas perspectivas eclesiales a partir de las lecciones de la historia y los desafíos del presente a la Iglesia.

Palabras clave: Conferencia Episcopal de Chile, Asambleas Plenarias, Iglesia y sociedad, Teología de los signos de los tiempos.

Abstract: In November 2010, the 100th Plenary Assembly of the Bishops' Conference of Chile was held. On the occasion of this symbolic event, this paper presents the results of a study of the content of statements emanating from these episcopal assemblies. It first takes an overall historical look at the texts, sorted by decade, then moves on to highlight and briefly analyze their main theological points. Finally, to conclude, there is a reflection on some ecclesial perspectives coming from the lessons of history and the present challenges to the Church.

Keywords: Bishops' Conference of Chile, Plenary Assemblies, Church and society, Theology of the signs of the times. 